\title{
Researchers working with city administrations: Reflecting on transdisciplinary collaboration under conditions of shared goals but different constraints
}

\author{
Robert Home ${ }^{1}\left[\right.$ D $\cdot$ Nicole Bauer ${ }^{2}$ \\ Accepted: 12 July 2021 / Published online: 23 July 2021 \\ (c) The Author(s) 2021
}

\begin{abstract}
Academics and city administrations generally agree that environmental management decisions should be science based, which suggests the value of collaboration between city officials and researchers. Such collaboration, termed "ecology with cities", is an example of translational ecology that should integrate ecological and social sciences to inform decision-makers. However, there has been insufficient reflection on whether ecology with cities achieves the expected development of practical socialecological knowledge for the common good. We addressed this gap by asking city officials and researchers, in Switzerland and with whom we have collaborated in the past, about their motivations for, and experiences with, transdisciplinary collaboration. The respondents reported largely overlapping goals and an awareness of the mutual benefits of accessing the skills and resources of the other group. However, the reflections also unearthed latent tensions related to insufficient mutual awareness of institutional boundaries and limitations. We conclude that researchers should try to include collaboration partners who have experience in translational ecology practice and should establish learning processes early in a collaboration. Building good working relationships with city administrations and establishing such processes would facilitate the creation of realistic mutual expectations in which institutional limitations are considered so that common goals of maintaining or improving the ecological quality of cities can be amicably reached.
\end{abstract}

Keywords Translational ecology $\cdot$ Transdisciplinary $\cdot$ Urban ecology $\cdot$ Collaborative research $\cdot$ Ecology with cities

\section{Introduction}

We live in a rapidly urbanizing world. Intensification of the built environment brings pressure on decision makers to use green spaces within urban areas for development, which has potentially negative consequences for both urban nature and residents (Home et al. 2010). The defence and preservation of urban green spaces, such as parks and gardens, is typically the responsibility of designated city departments, such as Departments of Recreation and Parks

Robert Home

robert.home@fibl.org

Nicole Bauer

nicole.bauer@wsl.ch

1 Research Institute of Organic Agriculture (FiBL), Ackerstrasse 113, Postfach 219, 5070 Frick, Switzerland

2 Swiss Federal Institute for Forest, Snow and Landscape Research (WSL), Zürcherstrasse 111, 8903 Birmensdorf, Switzerland and Environmental Management Divisions, which in Swiss cities are collectively referred to as 'green' departments. Communication between personnel in such departments and researchers has never been more vital because environmental problems, such as those caused by the loss of urban greenspaces, are associated with complexity, uncertainty, and irreversibility, so their solution requires collaborative, science-based management (Home et al. 2010). In the case of preservation of urban greenspaces, the interface between science and society occurs in the green departments who design and communicate policies and make management decisions about the threatened green spaces. However, green departments require sound ecological arguments to support their decisions and to counter arguments that cities are environments in which only human infrastructure needs should be considered. Furthermore, Safford et al. (2017) caution that innovative, participatory, and multiparty approaches are required to solve the environmental problems faced by society, which can be interpreted as a call for an "ecology with cities" (Byrne 2021). 
Ecology with cities describes the collaborative interaction between researchers and other stakeholders, including residents, landscape managers, city administrations, and policy makers to solve problems in urban social-ecological systems (Byrne 2021). Key arguments for the collaborative approach include the principle that constructive input from all relevant communities of knowledge, guided by shared goals, norms, and visions, will increase the legitimacy, ownership, and accountability of the solution options for complex sustainability problems (Lang et al. 2012). Collaboration in urban ecological research and management thereby enables complexity to be grasped, diverse perspectives to be considered, abstract and case-specific knowledge to be linked, and descriptive, normative, and practical types of social-ecological knowledge to be developed for the common good (Pohl 2011). Ecology with cities is inherently transdisciplinary with "researchers and extra-scientific actors [engaging in] mutual learning processes" (Jahn et al. 2012, p.3) to focus on the collaborative translation of scientific data into management decisions and policies, such as those regarding ecosystem services: what Enquist et al. (2017) refer to as 'translational ecology'. They point out that translational ecology involves ecologists integrating ecological science with the full complement of social dimensions that underlie today's complex environmental issues so that decision making is informed by ecological knowledge (Enquist et al. 2017).

An alternative approach to leaving ecologists, such as conservation biologists, to shoulder the burden of integrating ecological science with the social dimensions in translational ecology research is for inter- or multi-disciplinary teams of both natural and social scientists to address the 'scientific' side of ecology with cities. Such collaboration removes the need for natural scientists to gain the skills of social scientists and vice versa. Lang et al. (2012) appear to agree and demand the inclusion of all relevant communities of knowledge, including from outside the scientific community, for transdisciplinary research in sustainability science to reach its potential. However, this implicit need for collaboration between ecological and social researchers and representatives of city administrations has led to surprisingly little reflection on whether the interactions lead, in practice, to the outcomes that Pohl (2011) suggests should be the case. Hallett et al. (2017) point out that there are rarely professional incentives for engagement between ecologists and stakeholders, such as city administrations. Such reflection should also consider the motivations for collaboration from the point of view of both researchers and green departments and whether the interactions lead to mutual achievement of goals.

The aim of this contribution is to respond to an invitation to submit a reflection paper in which we were asked to describe how we had successfully engaged with people in the Better Gardens project (www.bettergardens.ch). However, to get more diverse and richer insights, we decided to include not only our experiences from the single project but from the collaborations of the last 20 years. To address these aims, we reflect on the motivations, goals, and experiences of collaboration from the points of view of Swiss researchers and representatives of Swiss city green departments. Although this case study is not intended to be representative, the reflection is expected to facilitate identification of enablers and barriers to implementing Enquist et al.'s (2017) translational ecology in other contexts and provide some lessons and guidance to members of the scientific community who wish to work in, and with, cities.

Here, we do not attempt to address the benefits and challenges of transdisciplinary research, as that would be a different exercise, but rather focus on the experience at the interface of science and practice. In other words, we reflect on Enquist et al.'s (2017) translational ecology but with transdisciplinary research teams. Our position in writing this reflection is based on around 20 years of experience as social science researchers working on various projects within cities in collaboration with representatives of city administrations and ecological researchers. These research projects ranged from small collaborations within the framework of the research components of master's degrees through larger transdisciplinary projects in multiple cities with multiple researchers, from disciplines including conservation biology, population biology, soil science, sociology, and environmental psychology (for an overview, and to access resulting publications, please refer to the personal home pages of the authors). The majority of the collaborations have been researcher driven, meaning that the researcher, or team of researchers, approach a city administration with an existing, and funded, project, although some have been jointly developed in collaboration with city administrations, and others have been initiated by the city with researchers approached to do 'the science part'.

To generate insights about the motivations, goals, and experiences of collaboration, we consulted six representatives of city green departments and six researchers (four biologist/ecologists, a soil scientist, and a sociologist) from both public and private research institutions in Switzerland with whom we have collaborated in the past. We asked them to describe, in an email, 1) their experiences of city/science collaboration and 2) their motivations and goals for collaborating. The responses were then coded, grouped by theme, and synthesized to give an overview. Labelling the responses according to whether they came from a researcher or a city administration enabled some evaluation of whether both groups share any common understanding about collaboration. These respondents, from four Swiss cities and three research institutions, were not selected systematically and are not intended to be representative. Instead, they are 
people with whom we have worked together in our own research in translational urban ecology in the past. Furthermore, the responses have been evaluated subjectively and, although we have attempted to let our respondents speak in their own words, interpreted in light of our own personal experience.

\section{Reflections on collaboration}

"Ecology with cities" projects require an understanding that city administrations are not homogenous. Within city administrations, competition exists for how to use scarce land resources, with green departments arguing for conservation and biodiversity outcomes, while other departments argue for development of built infrastructure. Ecological research provides green departments with 'ammunition' in these disputes. One respondent from a city administration pointed out, "We try to convince other parts of the administration, citizens, or businesses of our opinion on what we consider the best solution for the given problem, using scientific results as a support for our arguments". The participating researchers appear to be well aware of this position and often point out, as one respondent did, the need "for a city to understand how green and open spaces function from an environmental and ecological perspective" so that the researchers can provide "important, evidence-based arguments for a city" to use. Researchers expressed the need for implementation measures to be communicated so that the people understand and accept them. In this way, the goals of the city green departments and the goals of the researchers strongly overlap, but both city administrations and researchers acknowledged the difficulty of creating a "link between theory and reality", and point out that it is "challenging to boil down the results for practical implementation". However, awareness of the overlapping goals leads researchers to place importance on the research remaining practically relevant, with the implicit expectation, or rather hope, that city administrations might implement the scientific results.

The goals for collaboration can be seen as recognition of the usefulness of ecology-based research to inform city administrations and aid in decision making so that ecology may indeed be translational (Enquist et al. 2017). The respondents from Swiss green departments expressed the opinion that science and data provide the basis for their daily work and reported that they use scientific results to orient, and sometimes reorient, projects and strategies. We understand, anecdotally, that ecological data does not always get integrated in urban planning and design in other contexts, such as the US, and acknowledge that the integration may be challenging in Switzerland as well. For example, sufficient data may simply not be available or may not be translated into a form that is useful for city administrations.
Nevertheless, city administrations are motivated to use what data are available because scientific results can help them achieve their goals and can also be used to give legitimacy to management and resource-allocation decisions by explaining the scientific basis for the decisions to stakeholders. Based on specific mandates to foster biodiversity, such as Berne's "Urban Biodiversity Concept" (Tschäppeler 2012) and Zürich's "Biodiversity: Wealth for Zürich" strategies (Zürich City 2010), the job descriptions of representatives of Swiss green departments typically include the requirement to make the best possible decisions to encourage biodiversity; within the constraints of citizens' needs, legal requirements, and scarce resources.

Researchers similarly see the value of supporting decision-making by providing relevant scientific results, such as alerting city administrations to "burning issues", or providing technical solutions for specific cases, such as methods for carbon sequestration. One researcher, for example, claimed they provide "scientific arguments as a basis for management and planning decisions". However, another pointed out that "an administration which wants as little disruption as possible_perhaps for legitimate reasons_has less to gain" from translational ecology. Researchers take the general position that city administrations should take more time to innovate and apply research results that ultimately achieve a greater benefit for the public, although this position ignores the cities' institutional boundaries and limitations (Hallett et al. 2017). For example, a Swiss municipality is legally obliged to undertake expensive remedial actions if traces of heavy metals in soils are found to exceed prescribed limits, which are lower for green spaces than for sealed areas. In some cases, discovery of heavy metals in soil that only exceed the limits by a small amount can force the removal of a greenspace for economic reasons, which is in contrast to the goals of green departments.

In an effort to align goals and to understand institutional boundaries and limitations, responding researchers claimed to seek dialogue with city administrations early in the research design phase of a project and point out the mutual benefits of collaboration. City administrations "can hear the state of the art at national and international level and scientists can better understand the needs of the administration and try to integrate them into their research". However, one respondent from a city administration observed that the administrations "know more about what is going on in science (in terms of study results) than the scientists know what is being put into practice and where the relevant questions are". This discrepancy probably reflects a divergence in the performance evaluation criteria between employees of cities and research institutes, with both institutions subject to institutional boundaries and limitations (Hallett et al. 2017). For example, city administrations are interested in results that lead to practical and visible applications, within short 
time frames and specified budgets. In this case, the ability to adjust research methodologies to produce fast results for purposes of good collaboration are limited by the imperative to maintain fidelity to scientific rigour and to follow the principles of good experimental design. A further example of an institutional limitation is that researchers are bound by the need to satisfy funding bodies with their scientific output, which is commonly expressed as the number of scientific publications, rather than practical output, such as the number of successful collaborations with practitioners.

These issues notwithstanding, there are practical reasons for collaboration. Researchers expressed the wish to access city resources, such as maps, databases, local knowledge, and networks. Furthermore, it was considered an act of courtesy to inform city green departments when a scientific study was being undertaken within an administrative district, especially when data were being collected in public spaces. As one researcher noted, "To gain access to services or actors is important for my research. Here the administrations have a gatekeeper function". City administrations also have practical reasons for collaboration in that they can access other competences, such as in methodologies and analysis, that they might otherwise not have the resources to engage. One respondent from a green department commented: "We depend on research results to get our work done in the right place, with the right priorities and objectives" but to do that, "cooperation must be very close... we need data, scientific advice, [and] background information [from] studies that we can't do by ourselves".

\section{Tensions in collaboration}

Both researchers and city administrators were generally positive about previous experiences of cooperation and used terms such as "constructive", "respectful", and "motivating". However, when interpreting this result, we should remember that people for whom collaboration was unfruitful or annoying, or just did not take place, were not asked for their opinion so we are limited in our ability to comment on how such unwillingness to collaborate by city officials could be overcome. The respondents in this survey were those with whom we have experience collaborating, and who we knew to be open to collaboration between city administrations and researchers, so it is not surprising that the attitudes were generally positive. Tobias et al. (2019) similarly found that experience with collaboration tends to lead to more positive attitudes towards transdisciplinary principles and to a higher likelihood of collaboration in the future. However, even within this group of colleagues with a history of working together, some differences in the working worlds were identified and there appear to be insufficient mutual understandings of the constraints they each face.
Some difficulties were noted, politely expressed as "different perspectives", on issues and topics that made cooperation "exciting". Stokols et al. (2008) point out that contextual differences are inherent in transdisciplinary scientific collaboration, with the degree of contextual influence correlating with the degree of diversity of the perspectives held by the collaborators. In the experiences of respondents, these different perspectives sometimes led to confrontation, which in turn led to a need to "take the time to reflect with others about our practices". Among the sources of tension were the indicators used to demonstrate success, which are different between the collaborating institutions. A key indicator of success in scientific institutions is the number of scientific publications resulting from a project rather than the degree to which the recommendations have been implemented or whether recommendations are practical. However, some voices in Swiss academic circles propose that practical implementation should carry more weight in the evaluation of scientific projects (Arlettaz et al. 2010) but it is unlikely that either type of institution can change their evaluation criteria, at least in the short term. On the other hand, success in a city green department is measured by the participation and acceptance of interventions, along with the practicality of implementation and the ecological outcomes. Stokols et al. (2008) suggest that collaboration under conditions of such widely divergent institutional contexts will inevitably lead to conflict and tensions unless members of a collaboration establish familiarity with each other's way of thinking, such as through the prolonged and regular exchange of ideas and the establishment of structures to create "collaboration readiness" (pp. 105).

Ecological research in cities takes time, and city administrations commonly need the results in a considerably shorter time-period than is practical for researchers, as emphasized by one respondent: "We often need quick and specific answers and can't always wait for final results". Representatives of city administrations often perceive researchers as service providers for the public because they are often, either directly or indirectly, financed by taxpayers' money. Researchers, on the other hand, would like to see their recommendations implemented with city resources that might simply not be available. Translational ecologists working in cities often recommend that city green departments should "put much more resources in a peculiar project, [but] it is not always possible" and the scarcity of resources means that there is "too little integration of scientific results". These differences can lead to frustration on both sides and a feeling on the side of researchers that city administrations are "not really interested in science ". City representatives point out: "we have too much work with our daily business and only little time for innovation". Researchers complain that it sometimes needs a long time before cities answer and that it "looks like they are overwhelmed by other work, [with] not much 
time to consider also outcomes from science". This, however, reflects a common misunderstanding about what is actually feasible and implementable by public administrations (Harris 2012), with researchers often failing to understand that city administrations also face, sometimes severe, limitations in time, financial, and spatial resources.

\section{Relieving tensions with mutual understanding}

Among the stated motivations for finding common ground was that goals are often shared by individuals with similar interests. City green departments see researchers as a potential resource in their competition for land uses and expressed the opinion that science and data provide the basis for their daily work by orienting, and sometimes reorienting, projects and strategies. Scientific results can also be used to give legitimacy to management and resource-allocation decisions by explaining the scientific basis for the decisions to stakeholders. On the other hand, researchers, at a personal level, want to see their research results implemented in practice, which is not usually a measure of academic success, and there are rarely academic resources for implementation of ecological projects. Researchers are therefore reliant on others to implement the results, and cities are a good candidate.

Schneider and Buser (2018) suggest that methodologies for defining research-related key questions, communicating different views and time frames, and creating common understandings should be negotiated between the participants: in this case, researchers and city administrations, at the beginning of a project when interaction and cooperation should be particularly close. This was reported to be seldom the case in reality, with many collaborations going ahead with few efforts made to structure mutual learning in a way that can enable both groups of participants to really understand the needs and constraints of the other. The clear remedy to this is to commit resources to establishing such structures early in a collaboration so that the common goals and different skill sets that each party can bring can be recognised and discussed. A further benefit of the early negotiation of processes and structures to enable common understanding is that it will facilitate recognition of the differing constraints faced by collaborators from different institutional settings with different institutional boundaries and limitations, such as time scales and financial resources, pointed out by Hallett et al. (2017) before misunderstandings become entrenched.

\section{Conclusions}

This contribution is a synthesis of opportunistic observations rather than conclusions drawn from systematic study, with the additional limitation that it represents experiences found in a few cities in one country. This contribution can therefore be used as a foundation for future researchers to create a systematic study with a uniform survey designed to gain specific insight from a much wider array of test subjects. Nonetheless, we believe these reflections may be informative for researchers intending to conduct ecological research in cities as well as for city officials who wish to work with researchers to support management and design with scientific knowledge. Indeed, the agreement between the presented results and the results of prior research suggests that the findings presented here may be familiar to those working, or intending to work, in translation ecology.

Ongoing collaborations between the four cities and three research institutes in Switzerland that participated in this case study have been friendly and fruitful over a long period of time, which is probably due to the large overlap in goals and a genuine will to collaborate. Both researchers and members of city green departments share a common interest in nature conservation within the cities and agree on the desirability of sensitising urban populations to conservation issues (Bauer 2016). The translational ecology approach, with researchers from different scientific disciplines collaborating with Swiss urban green departments has, at least to some extent, provided the city green departments with scientific arguments to support ecological actions in contested urban spaces. Meanwhile the collaboration has provided researchers with a setting for their research along with tangible support and access to some city resources. Furthermore, the collaborations have enabled some academic results to be implemented in the real world: an outcome that is not always possible within research budgets.

Despite the successes of these collaborations, this collective exercise in reflection also revealed some latent tensions and some lessons for researchers who are interested in working with cities. Prior experience by a city official in working with researchers, and especially those with an interest in ecological research, demonstrates a willingness to collaborate and will probably have led to some experience, and therefore some awareness, of the institutional constraints faced by researchers. Therefore, seeking experienced collaborators, both within research teams and within the targeted city's administration, is a good starting point for enabling fruitful future ecology with cities (Byrne 2021). Consideration of the differing viewpoints held by the city administrations and the academic world could smooth the path of collaborative research efforts by avoiding potential problems and building a good working relationship based on mutual understanding. Early collaboration should therefore include definition of individual goals, along with definitions of each participant's rights, roles, and responsibilities so that misunderstandings can 
be avoided. Time is a valuable resource and is particularly scarce within city administrations, so a further recommendation is to allocate sufficient time to creating learning processes and facilitating an early mutual understanding of the institutional boundaries and limitations (Hallett et al. 2017). Furthermore, this time should be allocated early in the project and preferably in the project design phase. Such processes would enable mutual expectations to remain realistic, institutional limitations to be considered, and the common goals of maintaining or improving the ecological quality of cities to be reached with minimal frustration.

Acknowledgements We are grateful to our colleagues from research and from city administrations who freely gave their time to share their thoughts.

Authors' contributions Both authors contributed equally to conceptualisation; data collection, analysis, and interpretation; and writing.

Funding Open Access funding provided by Forschungsinstitut für biologischen Landbau (FiBL). There was no external funding for this submission.

Availability of data and materials All data and materials will be made available on request.

\section{Declarations}

Ethics approval and consent to participate Ethics approval and consent to participate in this study were in accordance with Swiss law, and data were handled in accordance with the European General Data Protection Regulations.

Consent for publication Consent to submit for publication is with agreement of both authors.

Competing interests There are no competing interests.

Open Access This article is licensed under a Creative Commons Attribution 4.0 International License, which permits use, sharing, adaptation, distribution and reproduction in any medium or format, as long as you give appropriate credit to the original author(s) and the source, provide a link to the Creative Commons licence, and indicate if changes were made. The images or other third party material in this article are included in the article's Creative Commons licence, unless indicated otherwise in a credit line to the material. If material is not included in the article's Creative Commons licence and your intended use is not permitted by statutory regulation or exceeds the permitted use, you will need to obtain permission directly from the copyright holder. To view a copy of this licence, visit http://creativecommons.org/licenses/by/4.0/.

\section{References}

Arlettaz R, Schaub M, Fournier J, Reichlin T, Sierro A, Watson J, Braunisch V (2010) From publications to public actions: when conservation biologists bridge the gap between research and implementation. Bioscience 60:835-842

Bauer N (2016) Ökologisch wertvolle Stadtnatur - bedroht, geduldet, akzeptiert oder gewünscht? Ergebnisse der Projekte BiodiverCity und Better Gardens. Natur \& Garten 2(4):56-58

Byrne LB (2021) Ecology with cities. Urban Ecol

Enquist C, Jackson S, Garfin G, Davis F, Gerber L, Littell J, Tank J, Terando A, Wall T, Halpern B, Hiers J (2017) Foundations of translational ecology. Front Ecol Environ 15:541-550

Hallett L, Morelli T, Gerber L, Moritz M, Schwartz M, Stephenson N, Tank J, Williamson M, Woodhouse C (2017) Navigating translational ecology: creating opportunities for scientist participation. Front Ecol Environ 15(10):578-586

Harris G (2012) Introduction to the special issue: "Achieving ecological outcomes". Why is translational ecology so difficult? Freshw Biol 57:1-6. https://doi.org/10.1111/j.1365-2427.2012.02773.x

Home R, Bauer N, Hunziker M (2010) Cultural and Biological Determinants in the Evaluation of Urban Green Spaces. Environ Behav 42(4):494-523

Jahn T, Bergmann M, Keil F (2012) Transdisciplinarity: Between mainstreaming and marginalization. Ecol Econ 79:1-10

Lang D, Wiek A, Bergmann M, Stauffacher M, Martens P, Moll P, Swilling M, Thomas C (2012) Transdisciplinary research in sustainability science: practice, principles, and challenges. Sustain Sci 7(S1):25-43

Pohl C (2011) What is progress in transdisciplinary research? Futures 43:618-626. https://doi.org/10.1016/j.futures.2011.03.001

Safford H, Sawyer S, Kocher S, Hiers J, Cross M (2017) Linking knowledge to action: the role of boundary spanners in translating ecology. Front Ecol Environ 15:560-680

Schneider F, Buser T (2018) Promising degrees of stakeholder interaction in research for sustainable development. Sustain Sci 13(1):129-142

Stokols D, Misra S, Moser R, Hall K, Taylor B (2008) The Ecology of Team Science: Understanding Contextual Influences on Transdisciplinary Collaboration. Am J Prev Med 35(2):S96-S115

Tschäppeler S (2012) Biodiversitätskonzept: Teil 1: Stossrichtungen und Ziele, Direktion für Tiefbau, Verkehr und Stadtgrün, Bern. 21 Pages

Tobias S, Stroebele M, Buser T (2019) How transdisciplinary projects influence participants' ways of thinking: a case study on future landscape development. Sustain Sci 14(2):405-419

Zürich City (2010) Biodiversität - Reichtum für Zürich. https://www. stadt-zuerich.ch/ted/de/index/gsz/beratung-und-wissen/naturschutz/ biodiversitaet.html\#mit_welchen_strategienverfolgenwirdieseziele, Visited 06.07.2021 